\title{
Adult and Pediatric All-Terrain Vehicle (ATV) Injury Patterns and Outcomes in a Community Trauma Center
}

Christopher Foote ( $\boldsymbol{D}$ christopher.foote@uhsinc.com)

South Texas Health System - McAllen

Xuan-Lan Doan

Valley Health System

Cheryl Vanier

Touro University Nevada

Carlos Palacio

South Texas Health System - McAllen

\section{Research Article}

Keywords: ATV, Trauma, Rural, injury patterns

Posted Date: February 21st, 2022

DOI: https://doi.org/10.21203/rs.3.rs-1229350/v2

License: @ (i) This work is licensed under a Creative Commons Attribution 4.0 International License. Read Full License 


\section{Abstract \\ Background}

All-terrain vehicle (ATV) crashes result in severe morbidity in trauma. Limited data on these injury patterns come from large urban academic centers, but studies show increased use of ATVs in small rural communities with fewer resources, where these injuries are more likely to be treated. This study uses injury patterns to determine impact on community trauma systems based on length of stay.

\section{Methods}

The trauma registry of a level II trauma center was reviewed for ATV crash patients from January 2015 to December 2020. Injury type and frequency were grouped by proportion and 95\% confidence interval based on 'score' method, and co-incidences were first screened with Fisher's exact test, with significant pvalue $<0.01$. Factors influencing length of stay in hospital/ICU were analyzed in a linear model and log-transformed dependent variable with significance based on sequential nested likelihood ratio analysis. Descriptive statistics were back transformed.

\section{Results}

Out of 7,787 trauma patients admitted during the study, 127 were involved in ATV crashes with 62 adults (age>18) and 65 pediatric patients. Injuries to skin/soft tissue and extremities were most common in both adult ( $68 \%$ and $42 \%, p<0.001)$ and pediatric $(56 \%$ and $38 \%, p<0.001)$. Paired injuries included head bleeds with skull fractures $(p<0.001)$ in both adults and pediatrics, pediatrics alone with spine and rib fractures $(p=0.01)$. Length of stay in hospital increased for extremity injuries in both groups (mean (SD); adults 5.8 (2.4) vs 3.0 (2.2) days and pediatrics 4.0 (2.2) vs 2.6 (2.0) days, $P=0.048$ ). Pediatric patients had shorter overall hospital length of stay compared to adults (mean (SD); 3.1 (2.1) vs 3.9 (2.4) days respectively, $P=0.009$ ). Mortality was low with only a single adult death.

\section{Conclusions}

The findings from our retrospective study among ATV-related injuries on a community level II trauma center demonstrates skin/soft tissue injuries and extremity injuries were most common. We can also predict prolonged hospital length of stay in those with extremity injuries and those older than 18 years of age, requiring greater resources with longer hospital stay. No factors were predictive of longer ICU stays and mortality was very low with a single adult death in our population.

\section{Background}

Studies have shown that there has been a steady rise in all-terrain vehicle (ATV) use within recent years, as well as an increased incidence of ATV-related casualties [1]. All-terrain vehicles (ATVs) are defined as any off-road vehicle with three or four low-pressure tires, a straddle seat, and handlebars. In 1985, the U.S. consumer product safety commission (CPSC) stated that ATVs were considered a hazardous product to consumers, due to all-terrain vehicles providing far less stability than other traditional road vehicles, thus leading to an overall increase in roll-overs and other motor vehicle accidents [1]. ATV crashes have therefore resulted in severe morbidity and mortality secondary to the high degree of injuries seen within this trauma sub-population [2].

All-terrain vehicles have been used in rural settings near smaller community hospital systems by farmers and ranchers as a hybrid truck or tractor vehicle for agriculture-related work. Recent literature has shown that ATV-related crashes are one of the leading causes of agriculture related deaths within the rural United States, and with nearly 60 million Americans living in these areas, there is a significant need to assess the injury patterns affecting this population [3, 4]. Previous literature related to this topic has come predominantly from large urban level I trauma centers $[2,5]$ associated with large academic institutions with minimal data encompassing ATV-related injury patterns within the suburban and rural populations. As these patients will more likely be treated in those suburban and rural hospitals, with typically fewer resources than larger academic centers, it is crucial to further understand the impact of the ATV-related injuries in the community hospitals in order to plan for resource allocation and development of standard treatment pathways.

Compared to level I trauma centers located in large metropolitan cities with larger overall patient volume, smaller rural-suburban trauma centers often deal with patients of similar acuity and large encatchment area, providing equitable injury-management while trying to more judiciously manage resources of the local population [2]. Length of stay is of particular interest to hospitals and patients as mitigating the cost burden of a long hospitalization more strongly affects resources of both parties [2] compared to level I trauma centers. ATV-related injury costs have skyrocketed from \$8,802 in 1995 to \$45,582 in 2016 [2] and will likely continue its trajectory. The United States continues to dominate the global demand for ATV use, and with predicted annual growth rate of $2.4 \%$, ATV-related accidents will continue to be an increasing cause of morbidity and mortality [6].

\section{Methods}

Western Investigational Review Board (WCG IRB) approval and waiver of patient consent were obtained for retrospective electronic database review of our own American College of Surgeons level II accredited trauma center. All methods were performed in accordance with the relevant guidelines and regulations. 
All queried charts were admitted trauma surgery patients involved in ATV crashes or ATV-related injuries between January 2015 and December 2020 . We first sought to characterize the patterns of injury. The frequency of each injury type was characterized for adults and pediatric populations by the proportion and $95 \%$ confidence interval $(\mathrm{Cl})$ based on the 'score' method $[7,8]$. Non-overlapping confidence intervals were used to indicate differences. The potential coincidence of injuries was screened using a Fisher's exact test for each pair with false discovery rate adjustment to control for family-wise error rate [9]. Pairs with $\mathrm{P}$-value $<0.01$ were noted.

We then attempted to determine any factors that influence length of hospital or intensive care unit (ICU) stay. Some of the presenting symptoms were rare ( $<5$ patients in pediatric and adult populations), including cardiac, spinal fractures, central nervous system/spinal cord injury, pelvis, intracranial bleed without fracture, and vascular injury. These were grouped into a single 'Other' factor as a presence/absence variable for the purposes of this analysis. Six pediatric and thirteen adult patients had one or more of the 'Other' factors. The remaining factors and population by age were used to predict the length of hospital stay or length of ICU stay in linear model and log-transformed dependent variable, which was a better fit than a generalized linear model with Gamma error [10]. Significance is based on sequential nested likelihood ratio analysis. Descriptive statistics were back-transformed for presentation. Analyses were done in Rv4.0.2 software (R Core Team (2020). R Foundation for Statistical Computing, Vienna, Austria).

\section{Results}

A total of 7,787 trauma patients were admitted during the 6-year study period with 127 involved in ATV crashes or had ATV-related injuries. There were 62 adults (age $\geq 18$ ) and 65 pediatric patients (age $<18$ ) with only one adult mortality. The general patterns of injury between pediatric and adult patients were similar as described in Table 1. For both pediatric and adult patients, injuries to the skin and soft tissue ( $56.5 \%$ and $68.3 \%$, respectively) and injuries to the extremities (38.7\% and $41.7 \%$, respectively) were the most common, with all others seen in fewer than $21 \%$ of patients. Additional issues that arose or were discovered on tertiary exam during the course of care, such as wound complication, readmission, cardiac issues, spine fractures, spinal cord injuries, pelvis injuries, head injury without fractures, and vascular injuries, were rare. For both pediatric and adult patients, there was no evidence that injuries tended to coincide for most pairs of variables in Table 1, with two exceptions. In both pediatric and adult patients, unsurprisingly, head bleed with fracture and skull fracture variables co-occurred ( $q$-value $<0.001$ ). For pediatric patients alone, spine fractures and rib injuries appeared together more than expected $(Q=0.010)$, although both were rare.

The predictors of both hospital and ICU length of stay are compared in tables 2 and 3 , categorized and compared by injury types. Only extremity injury was significant for predictor of requiring longer inpatient hospital admission ( $\mathrm{p}$-value $<0.001)$. The mean hospital and ICU length of stay with various injury types are further described on tables 4 and 5. Length of stay in hospital increased from those without extremity injuries versus those with extremity injuries (mean (standard deviation (SD)); adults 3.0 (2.2) days vs 5.8 (2.4) days; pediatric 2.6 (2.0) days vs 4 (2.2) days). This represents a smaller but still significant difference in pediatric versus adult patients $(P=0.048)$. No significant predictor was found for longer ICU length of stay due to specific injury. Pediatric patients had shorter overall hospital stays compared to adult patients (mean (SD); 3.1 (2.1) vs 3.9 (2.4); P=0.009).

\section{Discussion}

Whereas recent studies have used other parameters to determine length of stay, and other factors in a similar setting at a level I trauma center, this study focuses more on a community level II trauma center where there is a paucity of studies on ATV-related injuries [2, 5, 11]. Similar to both urban and rural level I trauma centers, ATV-associated injury patterns are significantly morbid in trauma patients at level II trauma centers [2]. Rural ATV use and local treatment is important as ATV injuries are the second most common source of agricultural injury and $63 \%$ of occupational agricultural fatalities [3].

In a report by Mullins, et al. it is reported that fifty percent of off-road ATV crashes in their study are definitively treated at local rural level III or IV hospitals with the majority of deaths occurring in the emergency department [12]. Mortality of ATV injuries is low with reports between 0.3-2.6\% [2, 5, 11-13] with the highest number of mortalities in the state of Texas [1] where our study data was obtained and is well known for its agriculture and large rural land area.

Agricultural injuries include ranching and farming activities where use of an ATV is an effective tool for working on uneven and variable terrain that make working with a truck or tractor difficult. The ATV operator uses 'active riding' requiring continuous bodily adjustments with the pelvis and torso laterally and move vertically up and down from the seat to maintain balance while driving [14]. Two types of ATVs are described: sport ATVs (category S) and utility ATVs (category G), with both designed for a single rider [3]. Sport ATVs have small or no-load racks, no winch or hitch, and are rear-wheel drive. Utility ATVs usually have front and rear racks for carrying loads, mounting equipment or hitches for pulling implements or tanks, four-wheel drive, winches, and automatic transmissions. The towing of spray tanks and shifting fluid changing the center of gravity over the terrain has a high likelihood of ATV rollover with over one third of ATV-related fatalities on farms involving a sprayer [3,14]. Both ATV types may be used in rural locations for work and recreation, but rollovers are more common in farm workers where they are pinned under the vehicle and die due to compression asphyxia [3]. Recreational riders drive faster and lose control, ejecting the operator and hitting stationary objects with head injuries being the leading cause of death [3, 12].

Despite the high impact of ATVs on agricultural injuries which are typically compiled by the AglnjuryNews database using publicly available resources, ATVs as off-road use vehicles are regulated by the CPSC with variable definitions of vehicle types and compiled with on-road incidents showing an inadequate 
surveillance of all ATV incidents [14]. Using geospatial mapping, Qin et al. studied ATV crashes throughout lowa to determine relationship with rurality [13]. They found $74 \%$ were rollover incidents and $25 \%$ of all ATV crashes occurred on roads, where both paved and unpaved roads were greater risks than off-road use. Due to the large low-pressure tires with knobby grooves, narrow track width, short wheelbase, and high center of gravity, they are not designed for effective road mechanics and are more likely to rollover $[3,14]$. Rural roads with lower traffic density and less paved traction should not be considered safer [13] for the ATV operator as there are different risks and mechanics that the recreational rider may not be adjusted to as ATVs can reach and exceed 60 miles per hour ( $\mathrm{mph}$ ) and usual farm use has been reported at approximately $35 \mathrm{mph}$ [3].

Mortality has been shown to decrease with proper protective equipment, especially with studies on pediatric populations and helmet use $[1,3,15,16]$. Therefore, nonlethal injuries therefore have remained a significant problem with ATV use and subsequent hospitalization. Although this study did find that age and injuries to the extremity tend to be the most common predictor of hospitalization time in both pediatric and adult populations, there was a significant difference in the length of stay between both groups. The results of this study show that both adult and pediatric patients with injuries to the extremity had an increased hospital length of stay than those without. Furthermore, it was found that adults tend to have a co-occurence of head bleeds and skull fractures whereas pediatrics had a co-occurence of spine fractures and rib injuries.

The study by Miller to try and predict length of stay and hospital charges was performed in a similar region of the country, in Northeast Texas, and used Injury Severity Score (ISS), GCS (Glasgow Coma Scale), and vital signs [2]. Patient vitals and GCS are transient, without context, and not necessarily representative of severity of injury, whereas ISS attempts to provide a metric to do just that. However, the aggregate ISS does not delineate injury types that may require specialty surgical intervention or ICU level care which may prolong hospital stay for operating time or logistical resources for overall management of injuries sustained. Therefore, we included injury type so that it might be used in the future as an adjunct category to help predict hospitalization time. Surprisingly, neither specific injuries nor comorbidities were significant enough to determine ICU stay. More stringent or currently untracked data collection may be necessary for use in the future to help determine what other factors might correlate with ICU length of stay.

The most recent statistics by the CPSC in 2017 shows that there were about 93,800 ATV-related emergency department related injuries in the U.S. with $26 \%$ of those being children younger than 16 years old [1]. Of the 93,800 recorded visits, $83 \%$ were discharged the same day while $15 \%$ were hospitalized. Most of these injuries included the arm (29\%), head or neck (29\%), leg (21\%), and torso (20\%) indicating extremity related injuries were the most prevalent. Similar to the study by Butts, et al. in 2020 at an urban level I trauma center, extremity injuries were also the most common ATV-related injury pattern seen [11]. The relationship presented in another study by Butts, et al. in 2019 of a 12-year review of ATV and dirt-bike injuries together as 'off-road vehicles', compared injury variables in rural vs urban level I trauma centers, and had shown a significant increase in overall extremity related injuries in the urban setting compared to those of their rural counterparts. Irrespective of these findings in relation to our rural level II trauma center, initial appearance of type and extent of injury can often influence the decision for whether a patient is diverted to a larger institution able to provide the suspected level of care needed for definitive patient management by prehospital providers.

Although it is difficult to standardize initial documentation due to the variability of multiple hospital systems, utilizing standardized tools could be used as indicators to help mitigate the variability of stated trauma severity. The use of injury severity score (ISS) and GCS in conjunction with specific trauma metrics including injury type in a larger view may be used as a tool to further predict patient length of stay in future studies. In addition, there are multiple patient specific socioeconomic factors not addressed that may potentially prolong hospital length of stay. Further research is needed to control these variables and improve the power of future studies.

\section{Conclusions}

Findings from our retrospective study revealed that among trauma patients involved in ATV crashes, injuries to skin/soft tissue and extremities were the most common in both adult and pediatric populations. Injury variables that predicted length of stay for both pediatric and adult patients were skin/soft tissue injuries and injuries to the extremities. Overall hospital length of stay was shorter in pediatrics compared to adult populations (3.1 vs 3.9 days, respectively), with overall patient mortality being extremely low (one adult death). There was no significant finding for predicting ICU length of stay. Adult patients and extremity injuries related to ATV crashes were significant predictors for increased hospital length of stay.

\section{Abbreviations}

ATV: All-terrain vehicle

Cl: Confidence interval

CPSC: U.S. Consumer Product Safety Commission

GCS: Glasgow Coma Scale

ICU: Intensive care unit 
IRB: Investigational review board

ISS: Injury Severity Score

MPH: miles per hour

SD: standard deviation

U.S.: United States

\section{Declarations}

\section{Ethics approval and consent to participate}

We obtained IRB approval from Western (WCG) IRB study \#1323813. Our facility has no internal IRB board and so was obtained through independent IRB service.

\section{Consent for publication}

Waiver of consent was obtained via Western (WCG) IRB.

\section{Availability of data and material:}

The datasets generated and/or analyzed during the current study are not publicly available, as they were compiled from our own patient records, but are available from the corresponding author on reasonable request.

\section{Competing interests}

We know of no conflicts of interests associated with the publication and there has been no financial support for this work that could influence its outcome.

\section{Funding}

There was no outside financial support for the production of this article.

\section{Authors' contributions}

CF and XD completed data collection. CF and CHP wrote the manuscript. CV performed statistical analysis. CHP was senior mentor for this paper. The author(s) read and approved the final manuscript.

\section{Acknowledgements}

Not applicable.

\section{Author Details}

'South Texas Health System Trauma Department, McAllen Medical Center, McAllen Texas; ${ }^{2}$ Valley Health System General Surgery Residency Program, Las Vegas Nevada; ${ }^{3}$ Touro University Nevada College of Osteopathic Medicine, Touro University Nevada

\section{References}

1. Topping J. 2018 Annual Report of ATV-Related Deaths and Injuries. The Consumer Product Safety Commission. https://www.cpsc.gov/s3fspublic/2018AnnualReportofATVRelatedDeathsandlnjuries.pdf?VGaf1cuZ_D0SGxct2eRpZUwcgME4LKDy. Published February 2020. Accessed September 27, 2021.

2. Miller A, Gallegly JD, Orsak G, Huff SD, Peters JA, Murry J, Ndetan H, Singh KP. Potential predictors of hospital length of stay and hospital charges among patients with all-terrain vehicle injuries in rural Northeast Texas. J Inj Violence Res. 2020 Jan;12(1):55-62. doi: 10.5249/jivr.v12i1.1219. Epub 2019 Dec 10.

PMID: 31822649; PMCID: PMC7001608.

3. Khorsandi F, Ayers P, Denning G, Jennissen C, Jepsen D, Myers M, Oesch S, Pate M, White DJ. Hazard Control Methods to Improve Agricultural All-Terrain Vehicle Safety. J Agromedicine. 2020 Nov 10:1-16. doi: 10.1080/1059924X.2020.1837705. Epub ahead of print. PMID: 33169657.

4. Holder K, Fields A, Lofquist D. Rurality Matters. The United States Census Bureau. https://www.census.gov/newsroom/blogs/randomsamplings/2016/12/rurality_matters.html. Published 2016. Accessed September 27, 2021.

5. Butts CA, Gonzalez R, Gaughan JP, San Roman J, Ross S, Porter J, Hazelton JP. Comparison of Urban Off-Road Vehicle and Motorcycle Injuries at a Level 1 Trauma Center. J Surg Res. 2020 Jan;245:373-376. doi: 10.1016/j.jss.2019.07.069. Epub 2019 Aug 16. PMID: 31425878.

6. All-terrain Vehicle Market by Type \& Application (Sport, Entertainment, Agriculture, Military \& Defense), Drive (2WD, 4WD, AWD), Engine (800cc), Fuel (Gasoline, Electric), Wheel Number, Seating Capacity, and Region - Global Forecast to 2025. Research and Markets - Market Research Reports. 
https://www.researchandmarkets.com/reports/5238098/all-terrain-vehicle-market-by-type-and?

utm_source=BW\&utm_medium=PressRelease\&utm_code=328nm4\&utm_campaign=1492678\%2B\%2BGlobal\%2BAllterrain\%2BVehicle\%2BMarket\%2B\%28202C

Published January 2021. Accessed September 27, 2021.

7. Newcombe RG. Two-sided confidence intervals for the single proportion: comparison of seven methods. Stat Med. 1998 Apr 30;17(8):857-72. doi: 10.1002/(sici)1097-0258(19980430)17:8<857::aid-sim777>3.0.co;2-e. PMID: 9595616.

8. Wilson, EB. Probable Inference, the Law of Succession, and Statistical Inference. Journal of the American Statistical Association. 1927; $22(158): 209-212$.

9. Storey J.D. (2011) False Discovery Rate. In: Lovric M. (eds) International Encyclopedia of Statistical Science. Springer, Berlin, Heidelberg.

https://doi.org/10.1007/978-3-642-04898-2_248

10. Basu A, Manning WG, Mullahy J. Comparing alternative models: log vs Cox proportional hazard? Health Econ. 2004 Aug;13(8):749-65. doi:

10.1002/hec.852. PMID: 15322988.

11. Butts CA, Gonzalez R, Nguyen L, Gaughan JP, Ross S, Porter J, Hazelton JP. Twelve-Year Review of Urban Versus Rural Off-road Vehicle Injuries at a Level 1 Trauma Center. J Surg Res. 2019 Jan;233:331-334. doi: 10.1016/j.jss.2018.07.061. Epub 2018 Sep 5. PMID: 30502267.

12. Mullins RJ, Brand D, Lenfesty B, Newgard CD, Hedges JR, Ham B. Statewide assessment of injury and death rates among riders of off-road vehicles treated at trauma centers. J Am Coll Surg. 2007 Feb;204(2):216-24. doi: 10.1016/j.jamcollsurg.2006.10.025. Epub 2006 Dec 14. PMID: 17254925.

13. Qin ES, Jennissen CA, Wadman CA, Denning GM. Using Geospatial Mapping to Determine the Impact of All-Terrain Vehicle Crashes on Both Rural and Urban Communities. West J Emerg Med. 2017 Aug;18(5):913-922. doi: 10.5811/westjem.2017.6.34404. Epub 2017 Jul 25. PMID: 28874944; PMCID:

PMC5576628.

14. Weichelt B, Gorucu S, Jennissen C, Denning G, Oesch S. Assessing the Emergent Public Health Concern of All-Terrain Vehicle Injuries in Rural and Agricultural Environments: Initial Review of Available National Datasets in the United States. JMIR Public Health Surveill. 2020 May 29;6(2):e15477. doi: 10.2196/15477. PMID: 32469319; PMCID: PMC7293057.

15. Doud AN, Moro R, Wallace SG, Smith MD, McCall M, Veach LJ, Pranikoff T. All-Terrain Vehicle Injury in Children and Youth: Examining Current Knowledge and Future Needs. J Emerg Med. 2017 Aug;53(2):222-231. doi: 10.1016/j.jemermed.2016.12.035. Epub 2017 Mar 1. PMID: 28258877.

16. Wymore C, Denning G, Hoogerwerf P, Wetjen K, Jennissen C. Parental attitudes and family helmet use for all-terrain vehicles and bicycles. Inj Epidemiol. 2020 Jun 12;7(Suppl 1):23. doi: 10.1186/s40621-020-00253-2. PMID: 32532340; PMCID: PMC7291627.

\section{Tables}


Table 1. Patient injury breakdown.

\begin{tabular}{|c|c|c|c|c|c|c|}
\hline & \multicolumn{3}{|c|}{ Pediatric } & \multicolumn{3}{|c|}{ Adult } \\
\hline & $\mathrm{n}$ & $\%$ patients & 95\% Confidence Interval & $\mathrm{n}$ & $\%$ patients & 95\% Confidence Interval \\
\hline Cardiac & 3 & $4.8 \%$ & $(1.3 \%, 14.4 \%)$ & 1 & $1.7 \%$ & $(0.1 \%, 10.3 \%)$ \\
\hline Spine Fractures & 5 & $8.1 \%$ & $(3.0 \%, 18.5 \%)$ & 2 & $3.4 \%$ & $(0.6 \%, 12.7 \%)$ \\
\hline Neuro/Spinal Cord & 0 & $0.0 \%$ & $(0.0 \%, 7.3 \%)$ & 1 & $1.7 \%$ & $(0.1 \%, 10.3 \%)$ \\
\hline Pelvis & 1 & $1.6 \%$ & $(0.1 \%, 9.8 \%)$ & 3 & $5.0 \%$ & $(1.3 \%, 14.8 \%)$ \\
\hline Head Bleed w/o Fx & 3 & $4.8 \%$ & $(1.3 \%, 14.4 \%)$ & 9 & $15.0 \%$ & $(7.5 \%, 27.1 \%)$ \\
\hline Head Bleed w/ Fx & 11 & $17.7 \%$ & $(9.6 \%, 29.9 \%)$ & 11 & $18.3 \%$ & $(9.9 \%, 30.9 \%)$ \\
\hline Ribs & 8 & $12.9 \%$ & $(6.1 \%, 24.4 \%)$ & 5 & $8.3 \%$ & $(3.1 \%, 19.1 \%)$ \\
\hline Lung (PTX, contusion, HTX) & 13 & $21.0 \%$ & $(12.1 \%, 33.5 \%)$ & 10 & $16.7 \%$ & $(8.7 \%, 29.0 \%)$ \\
\hline Skull Fractures & 12 & $19.4 \%$ & $(10.8 \%, 31.7 \%)$ & 10 & $16.7 \%$ & $(8.7 \%, 29.0 \%)$ \\
\hline Extremity & 24 & $38.7 \%$ & $(26.9 \%, 52.0 \%)$ & 25 & $41.7 \%$ & $(29.3 \%, 55.1 \%)$ \\
\hline Skin/Soft Tissue & 35 & $56.5 \%$ & $(43.3 \%, 68.8 \%)$ & 41 & $68.3 \%$ & $(54.9 \%, 79.4 \%)$ \\
\hline Face & 12 & $19.4 \%$ & $(10.8 \%, 31.7 \%)$ & 8 & $13.3 \%$ & $(6.3 \%, 25.1 \%)$ \\
\hline Abdomen & 7 & $0.3 \%$ & $(5.0 \%, 22.5 \%)$ & 7 & $11.7 \%$ & $(5.2 \%, 23.2 \%)$ \\
\hline Vascular & 1 & $1.6 \%$ & $(0.1 \%, 9.8 \%)$ & 2 & $3.3 \%$ & $(0.6 \%, 12.5 \%)$ \\
\hline Pertinent Comorbidity & 4 & $6.5 \%$ & $(2.1 \%, 16.5 \%)$ & 1 & $1.7 \%$ & $(0.1 \%, 10.1 \%)$ \\
\hline Wound Complication & 1 & $1.6 \%$ & $(0.1 \%, 9.8 \%)$ & 3 & $5.0 \%$ & $(1.3 \%, 14.8 \%)$ \\
\hline Compartment Syndrome & 2 & $3.2 \%$ & $(0.6 \%, 12.2 \%)$ & 2 & $3.3 \%$ & $(0.6 \%, 12.5 \%)$ \\
\hline Bleed & 0 & $0.0 \%$ & $(0.0 \%, 7.3 \%)$ & 1 & $1.7 \%$ & $(0.1 \%, 10.1 \%)$ \\
\hline Readmit & 1 & $1.6 \%$ & $(0.1 \%, 9.8 \%)$ & 5 & $8.3 \%$ & $(3.1 \%, 19.1 \%)$ \\
\hline Infection & 1 & $1.6 \%$ & $(0.1 \%, 9.8 \%)$ & 2 & $3.3 \%$ & $(0.6 \%, 12.5 \%)$ \\
\hline
\end{tabular}

Number and percent of patients presenting with problems and other issues that arose during their care for pediatric $(n=65)$ and adult $(n=62)$ patients. (Fx: fracture, PTX: pneumothorax, HTX: hemothorax, Neuro: neurologic.) 
Table 2. Predictors of hospital stay.

\begin{tabular}{|c|c|c|c|c|}
\hline Effect & Estimate & SE & Chisq & $\mathrm{p}$-value \\
\hline Intercept & 0.26 & 0.10 & & \\
\hline Age & -0.06 & 0.14 & 6.7 & 0.009 \\
\hline Head Bleed w/ Fx & 0.19 & 0.35 & 0.8 & 0.385 \\
\hline Ribs & -0.09 & 0.15 & 0.6 & 0.432 \\
\hline Lung (PTX, contusion, HTX) & 0.09 & 0.12 & 0.3 & 0.598 \\
\hline Skull Fractures & 0.23 & 0.33 & 0.1 & 0.800 \\
\hline Extremity & 0.46 & 0.10 & 23.6 & $<0.001$ \\
\hline Skin/Soft Tissue & 0.12 & 0.09 & 7.5 & 0.006 \\
\hline Face & 0.05 & 0.12 & 0.1 & 0.763 \\
\hline Abdomen & 0.15 & 0.14 & 2.2 & 0.142 \\
\hline Other & -0.14 & 0.10 & 6.5 & 0.011 \\
\hline Age ${ }^{\star}$ Head Bleed w/ fx & -0.08 & 0.38 & 0.0 & 0.828 \\
\hline Age*Ribs & 0.40 & 0.23 & 3.0 & 0.083 \\
\hline Age*Lung & -0.09 & 0.18 & 0.2 & 0.622 \\
\hline Age ${ }^{\star}$ Skull Fxs & -0.24 & 0.37 & 0.4 & 0.522 \\
\hline Age ${ }^{\star}$ Extremity & -0.26 & 0.13 & 3.9 & 0.048 \\
\hline Age ${ }^{\star}$ SkinSoft Tiss & 0.14 & 0.14 & 1.0 & 0.313 \\
\hline Age*Face & -0.04 & 0.17 & 0.1 & 0.804 \\
\hline Age*Abdomen & -0.01 & 0.20 & 0.0 & 0.947 \\
\hline $\mathrm{Age}^{\star}$ Other & -0.21 & 0.18 & 1.4 & 0.242 \\
\hline
\end{tabular}

The regression coefficient (estimate), standard error (SE) of the coefficient, chi-squared statistic (Chisq), and p-value are provided. All tests had one degree of freedom. (FX: fracture, PTX: pneumothorax, HTX: hemothorax, Tiss: tissue.) 
Table 3. Predictors of ICU stay.

\begin{tabular}{|c|c|c|c|c|}
\hline Effect & Estimate & SE & Chisq & $\mathrm{p}$-value \\
\hline Intercept & 0.19 & 0.10 & & \\
\hline Age & 0.07 & 0.14 & 1.3 & 0.257 \\
\hline Head Bleed w/ Fx & 0.57 & 0.37 & 3.2 & 0.075 \\
\hline Ribs & 0.00 & 0.16 & 0.9 & 0.345 \\
\hline Lung (PTX, contusion, HTX) & 0.16 & 0.13 & 3.0 & 0.083 \\
\hline Skull Fractures & -0.15 & 0.35 & 0.1 & 0.732 \\
\hline Extremity & -0.10 & 0.10 & 0.0 & 0.890 \\
\hline Skin/Soft Tissue & 0.10 & 0.10 & 1.7 & 0.195 \\
\hline Face & -0.03 & 0.13 & 0.3 & 0.595 \\
\hline Abdomen & 0.16 & 0.15 & 1.6 & 0.206 \\
\hline Other & 0.07 & 0.11 & 0.9 & 0.354 \\
\hline Age ${ }^{\star H e a d ~ B l e e d ~ w / ~ f x ~}$ & -0.36 & 0.40 & 0.8 & 0.374 \\
\hline Age ${ }^{\star}$ Ribs & 0.25 & 0.24 & 1.1 & 0.299 \\
\hline Age*Lung & 0.01 & 0.19 & 0.0 & 0.968 \\
\hline Age ${ }^{\star}$ Skull Fxs & 0.12 & 0.39 & 0.1 & 0.763 \\
\hline Age ${ }^{\star}$ Extremity & 0.17 & 0.14 & 1.5 & 0.215 \\
\hline Age $^{\star S k i n S o f t ~ T i s s ~}$ & -0.01 & 0.14 & 0.0 & 0.935 \\
\hline Age ${ }^{\star}$ Face & 0.18 & 0.19 & 0.9 & 0.355 \\
\hline Age*Abdomen & -0.06 & 0.22 & 0.1 & 0.793 \\
\hline Age $^{\star}$ Other & -0.45 & 0.19 & 5.6 & 0.018 \\
\hline
\end{tabular}

The regression coefficient (estimate), standard error (SE) of the coefficient, chi-squared statistic (Chisq), and p-value are provided. All tests are one degree of freedom. (FX: fracture, PTX: pneumothorax, HTX: hemothorax, Tiss: tissue.)

Table 4. Hospital length of stay for adult and pediatric patients.

\begin{tabular}{|c|c|c|c|c|}
\hline & Adult & & Pediatric & \\
\hline & Absent & Present & Absent & Present \\
\hline Head Bleed w/ Fx & $3.5(2.2)$ & $6.0(3.2)$ & $3.0(2.0)$ & $3.6(2.6)$ \\
\hline Ribs & $4.2(2.5)$ & $2.2(1.9)$ & $2.9(2.1)$ & $5.1(2.6)$ \\
\hline Lung (PTX, contusion, HTX) & $4.0(2.3)$ & $3.5(3.0)$ & $2.9(2.1)$ & $4.2(2.4)$ \\
\hline Skull Fracture & $3.4(2.2)$ & $6.4(3.1)$ & $3.1(2.1)$ & $2.9(2.4)$ \\
\hline Extremity & $3.0(2.2)$ & $5.8(2.4)$ & $2.6(2.0)$ & $4.0(2.2)$ \\
\hline Skin/Soft Tissue & $3.3(2.2)$ & $4.3(2.6)$ & $2.0(1.8)$ & $3.8(2.1)$ \\
\hline Face & $3.8(2.4)$ & $4.4(2.5)$ & $3.0(2.1)$ & $3.6(2.4)$ \\
\hline Abdomen & $3.9(2.4)$ & $3.7(3.2)$ & $3.1(2.1)$ & $3.0(2.7)$ \\
\hline Other & $1.0(1.0)$ & $1.0(1.0)$ & $1.0(1.0)$ & $1.0(1.0)$ \\
\hline
\end{tabular}

Mean (standard deviation) for hospital length of stay for adult and pediatric patients with different symptoms present or absent. (Fx: fracture, PTX: pneumothorax, HTX: hemothorax.) 
Table 5. ICU length of stay for adult and pediatric patients.

\begin{tabular}{|c|c|c|c|c|}
\hline & \multicolumn{2}{|l|}{ Adult } & \multicolumn{2}{|l|}{ Pediatric } \\
\hline & Absent & Present & Absent & Present \\
\hline Head Bleed w/ Fx & $0.8(0.9)$ & $4.2(1.8)$ & $1.4(1.3)$ & $3.2(1.5)$ \\
\hline Ribs & $1.1(1.3)$ & $1.2(1.1)$ & $1.5(1.3)$ & $3.9(1.6)$ \\
\hline Lung (PTX, contusion, HTX) & $0.9(1.0)$ & $2.4(1.9)$ & $1.3(1.2)$ & $3.8(1.4)$ \\
\hline Skull Fracture & $0.8(0.9)$ & $3.5(2.0)$ & $1.5(1.3)$ & $2.4(1.5)$ \\
\hline Extremity & $1.8(1.3)$ & $0.4(0.9)$ & $1.6(1.1)$ & $1.6(1.7)$ \\
\hline Skin/Soft Tissue & $1.0(1.1)$ & $1.3(1.4)$ & $1.1(1.0)$ & $1.9(1.5)$ \\
\hline Face & $1.0(1.1)$ & $1.7(2.3)$ & $1.4(1.3)$ & $3.2(1.4)$ \\
\hline Abdomen & $1.0(1.1)$ & $2.4(2.2)$ & $1.6(1.3)$ & $2.0(2.0)$ \\
\hline Other & $1.0(1.0)$ & $1.0(1.0)$ & $1.0(1.0)$ & $1.0(1.0)$ \\
\hline
\end{tabular}

Mean (standard deviation) for ICU length of stay for adult and pediatric patients with different symptoms present or absent. (Fx: fracture, PTX: pneumothorax, HTX: hemothorax.) 